\title{
Against Incapacitative Punishment
}

\author{
Zachary Hoskins \\ University of Nottingham
}

\section{Introduction}

Risk assessment is a widely accepted consideration in criminal sentencing. Many legal systems incorporate assessments of offender riskiness into sentencing guidelines. The rationale for such assessments is generally grounded in the frequently asserted punitive aim of incapacitation, whereby punishment aims to help reduce the risk of future criminal wrongdoing by removing supposedly dangerous individuals from situations in which they might be a threat to others. In this chapter, I argue that punishing to incapacitate people based on assessments of their riskiness is unjustified. The argument I defend has been gestured at elsewhere (see, e.g., Robinson 2001: 1446-47), although as far as I know it has not been given the extended treatment it receives here. More importantly, to my knowledge the objection has never been successfully answered, which is troubling given the prevalence of risk-based sentencing grounded in the logic of incapacitation.

It is worth highlighting at the outset that my target in this chapter is risk assessment in the service of sentencing for which incapacitation is the central or sole rationale. Considerations of risk reduction may play other roles in criminal punishment: namely, punishment might help to reduce the risk of future criminal offending by serving as a credible deterrent threat to potential offenders, by reinforcing social norms, or by helping to reform offenders (see, respectively, Bentham 1996: chs. 13-14, Ewing 1927, Hampton 1984). In each of these cases, punishment aims to reduce the risk of crime and protect public safety by providing compelling reasons for 
people not to offend (or reoffend): deterrence aims to provide a prudential reason, namely, the onerousness of punishment; norm reinforcement and offender reform instead operate in the currency of moral reasons. The logic of incapacitation, by contrast, does not involve any appeal to reasons, whether prudential or moral; rather than aiming to provide some reason not to $\theta$, incapacitation aims simply to remove $\theta$ from the set of options among which the agent is free to choose. For reasons that will become apparent, the argument considered here does not apply to deterrence or, on some accounts, norm reinforcement or offender reform as rationales for punishment. Also, we might accept as a constraining principle that sentences should not be so severe that they tend to increase the risks of future criminal wrongdoing. The argument in this chapter does not address this sort of risk-based constraint.

In what follows, I first set the stage by briefly discussing some common lines of objection to incapacitative sentencing, based on the imprecise nature of risk-assessment tools and the perceived tensions between risk reduction and retributivism. Next, I set out a different argument against incapacitative punishment, one that in my view cuts more deeply than arguments based on concerns about risk-assessment tools or retributivism. After setting out the case against incapacitative punishment, I consider and respond to potential responses that defenders of the practice might offer. Ultimately, I conclude that all but one of these defences is unsuccessful, and that the remaining defence succeeds to such a limited extent as to be likely unsatisfying for proponents of incapacitative punishment.

\section{Standard objections}

Challenges to incapacitative punishment have commonly taken two general forms. First, many have objected to incapacitative sentencing on grounds that risk assessment is, to say the 
least, an imperfect science (see, e.g., Dubber 1995: 710-11, Zimring and Hawkins 1995: ch. 5, and Fazell, this volume). Historically, risk assessment tools have tended to overpredict the risk of recidivism by a significant margin. For example, a 2012 meta-analysis of 68 studies of commonly used risk-assessment tools found that 59 percent of people judged to be at moderate or high risk by violence risk assessment tools did not go on to violently offend; 77 percent judged to be at moderate or high risk by sexual risk assessment tools did not go on to sexually offend; and 48 percent of those rated moderate or high risk by generic risk assessment tools did not subsequently commit any offence (Fazell 2012; see also Fazell this volume, Cohen 1984: esp. 270-71, Monahan 1981: 73-80, 101-104; but see Lieb et. al. 1998: esp. 94-100). Setting sentencing levels according to risk-assessment tools that so drastically overpredict riskiness appears unjust in that it will lead to many offenders' serving sentences longer than the actual risks warrant. My focus in this chapter, however, is not on the imperfect science of risk assessment. Instead, I focus on the in-principle case against incapacitative sentencing. This line of objection would hold even if, counterfactually, risk assessment tools were perfectly accurate.

The other most common line of objection to incapacitative punishment focuses on the apparent tensions between punishment as a response to prior wrongdoing and prevention as concerned with averting future wrongdoing. This general worry manifests in various ways: Some critics claim that the concept of incapacitative punishment is incoherent, that punishment cannot be incapacitative, because punishment is for a past crime, whereas incapacitative detention or other measures are concerned solely with preventing future wrongdoing (see, e.g., Robinson 2001: 1432, Slobogin 2003: 12). This objection essentially aims to define away the problem, a move Hart (1959-60: 5) termed the 'definitional stop'. But as Hart recognised, we should be wary of attempts to settle normative debates by appeals to definition (ibid.: 5-6). The argument I 
offer below is not that incapacitative treatment cannot constitute punishment; rather, I contend that the rationale of incapacitation cannot justify punishment.

Others object that the aim of incapacitation will often prescribe sentences that violate the commonly accepted desert-based proportionality constraint — that sentences should be no more (and perhaps, no less) severe than is deserved given the seriousness of the crime and the offender's culpability (see, e.g., Robinson 2001: 1438-41, and Ryberg, this volume). Again, the worry here is that the rationale of incapacitation is purely forward-looking, whereas the desertbased proportionality principle is concerned with the relationship of the sentence to the prior crime to which it responds. And although it is of course possible that an offender might suddenly cease being dangerous at just the same time that he completes a deserved term of punishment, this would be merely a coincidence. When concerns of dangerousness and desert do not align, the rationale of incapacitation will prescribe apparent violations of the desert-based proportionality principle.

This worry is, I think, less problematic than it might at first appear. Hybrid theorists, at least, have a number of responses available. They might regard desert-based proportionality as asymmetrical, setting an upper limit but not a lower limit on sentencing severity (see, e.g., Armstrong 1961: 486-87, Corlett 2001: 78). Beneath the ceiling set by desert, sentences could then vary depending on considerations of risk. Alternatively, they might endorse 'limiting retributivism,' according to which there is not a specific deserved sentence for each crime, but rather a range of not clearly undeserved sentences (see, e.g., Morris 1974, Morris and Tonry 1990, Frase 2013). Within this range of not clearly undeserved sentencing options, considerations of incapacitation might play a role in determining precise sentence levels. Or there might be other ways of reconciling considerations of incapacitation and desert. For those 
who believe, as I do, that any successful justificatory account of punishment will need to incorporate various moral values, there will always be questions of how to resolve potential tensions among these values. The devil is in the details, of course, and we must assess pluralistic accounts as we find them; but in my view, the inevitable existence of such tensions does not pose an insurmountable challenge to hybrid theories generally, or in particular to theories that integrate considerations of incapacitation and retribution. At any rate, the argument that follows is not grounded in the challenges of integrating forward-looking and backward-looking elements into a unified theory.

\section{The case against incapacitative punishment}

A justificatory theory of punishment must answer a number of questions, but among the most crucial are these two: why is punishment justifiable in principle, and what sentences are justified in particular cases? Answers to these questions will vary depending on what rationale we cite for the practice and on what constraining principles we endorse. As Hart wrote, "in relation to any social institution, after stating what general aim or value its maintenance fosters we should enquire whether there are any and if so what principles limiting the unqualified pursuit of that aim or value" (Hart 1959-60: 8). ${ }^{1}$ I want to focus on the question of punishment's rationale. A compelling rationale is a necessary condition, albeit not a sufficient one, of punishment's justification. Essentially, the case against incapacitation as a rationale for punishment is that it is unable either to ground an answer to the question of punishment's in-

\footnotetext{
${ }^{1}$ Hart referred to what I have termed punishment's rationale as its 'general justifying aim.' I think his phrasing is unfortunate in two respects. First, the term 'aim' may seem to privilege consequentialist rather than retributivist answers to this question, whereas in fact punishment's compelling rationale may be a retributivist one. Second, characterising the aim as 'justifying' may suggest that the aim itself is sufficient to justify the practice, whereas in fact, whether punishment is justified will depend not only on there being a compelling rationale for the practice but also on punishment's not violating the rights of those punished or whatever other constraints we take to govern the practice.
} 
principle justification or to provide appropriate guidance about sentence severity in particular cases.

First, consider the question of why punishment is justifiable in principle. Importantly, to answer this question, we need to be clear about what we're aiming to justify. Criminal punishment, on common characterisations, is a burdensome response to criminal wrongdoing, imposed by a legal authority on the supposed perpetrator of the wrongdoing. But punishment is not merely burdensome, it is intentionally burdensome. In this respect, punishment is distinctive as a state institution. Other state practices, such as taxation, licensing fees, or the construction of airports or major highways near residential areas, will often be burdensome. But standardly, it is not the aim of such practices to burden those subject to them. This is not to say that legislators might not levy a new tax with the intention of harming those subject to it. But the standard purpose of taxation, to generate revenue to fund public goods, does not require that those subject to taxation are burdened by this. The same is true of licensing fees or major building projects near residential areas.

Punishment, however, is different. Punishment's burdensomeness is not merely incidental to the practice; it is essential to it (Benn 1985: 8). This conceptual point has important normative implications, as it helps to illuminate the distinctive moral challenge presented by punishment.

As David Boonin writes:

It is one thing to justify the claim that it is morally permissible for the state to act in various ways while foreseeing that so acting will cause some of its citizens to suffer (e.g., changing the speed limit, modifying air pollution standards, imposing new regulations, raising taxes, or conscripting soldiers, all of which cause harm to a significant number of people). It is quite another to justify the claim that it is morally permissible for the state to act in various ways in order that some of its citizens will suffer. Yet, this is precisely what must be justified in order to justify punishment (Boonin 2008: 16). 
A normative account of punishment, then, is not merely an attempt to justify burdensome state treatment of some of its members; it is an attempt to justify intentionally burdensome treatment. And as I wrote before, a necessary condition in the justification of such treatment is that there is some sufficiently compelling rationale. ${ }^{2}$

Deterrence, retribution, and, on some accounts, norm reinforcement or offender reform are rationales geared toward justifying intentionally burdensome treatment of offenders. The logic of deterrence requires that punishment be onerous, so that the threat of punishment may be effective at dissuading potential offenders from carrying out their crimes (but see Hanna 2014). ${ }^{3}$ Meting out retribution for wrongdoing also requires that punishment be burdensome, as retributivists believe offenders deserve some form of hard treatment (or deserve censure that is communicated by hard treatment). And on at least some norm reinforcement or offender reform accounts, the onerousness of punishment plays a crucial role in spurring the community or the offender himself to consider the wrongfulness of the offender's conduct (on punishment's role in societal norm reinforcement, see Andenaes 1974; on its role in spurring offender reflection and reform, see, e.g., Duff 2001: esp. 106-112, or Hampton 1984). In each of these cases, the burdensomeness of punishment is necessary to its achieving its ends. And as Kant reminds us, to intend some end rationally commits us to intending the necessary means to that end (Kant 1996[1785]: 70). Thus insofar as we set, say, deterrence as our end, we are rationally committed

\footnotetext{
${ }^{2}$ It is important to distinguish the task of justifying a state's intentionally acting in burdensome ways from the task of justifying its acting in intentionally burdensome ways. The distinction matters, as a state may intentionally act in ways that are only foreseeably burdensome to its members (e.g., through taxation or licensing fees). But what is distinctive about punishment is that it is not just the state's act that is intended but the burdensomeness of the act. ${ }^{3}$ One might argue that the burdensomeness needed for deterrence is not intended, but merely foreseeable. After all, if the deterrent threat were perfectly effective, no punishment would ever be imposed; it is only when the deterrent threat is not perfectly effective that punishment will foreseeably be inflicted. Thus the burdens associated with punishment are foreseen but not intended. I have previously endorsed this line of argument (Hoskins 2011: 372-73, drawing on Benn 1958: 330). I now believe this was a mistake, however. Even if, in issuing a deterrent threat, the state does not intend the burdens that ultimately befall those who do not heed the threat, it remains the case that in actually imposing the sentences themselves, the state intends these to be burdensome so that they will function to maintain the credible deterrent threat.
} 
to intending the burdensome means necessary to achieve that end. The same is true of retribution and some norm reinforcement or offender reform accounts. And if setting these ends rationally commits us to intending the burdensome means necessary to achieving them, then these ends are at least the right kinds of rationales to figure in a justification of punishment as an intentionally burdensome practice. This is not to say that any of these ends is ultimately successful as a rationale for punishment, just that each is at least the right kind of rationale for the job, given the nature of what they aim to justify.

The rationale of incapacitating supposedly dangerous individuals, by contrast, is not the right sort of rationale to serve in a justification of punishment. This is because setting incapacitation as an end does not rationally commit us to intending that the means of incapacitation be burdensome. Confinement of a dangerous person, for example, is not made possible, or even more effective, by its being burdensome. The state could in principle incapacitate people effectively even if the conditions of confinement were so pleasant that neither offenders nor members of the public generally viewed being confined as burdensome. Of course, in practice incapacitation typically will be burdensome. But as with taxation or licensing fees, the aim of incapacitating dangerous people does not require that this be burdensome for them. Thus the rationale of incapacitation, unlike the rationales of deterrence or retribution, does not justify intending that the measures be burdensome. Although incapacitation is the right kind of rationale to serve as part of a justification of foreseeably burdensome involuntary confinement or other liberty restrictions, it is not the right kind of rationale to justify intentionally burdensome treatment, i.e., punishment.

Perhaps, though, incapacitation could still function as an important consideration in sentencing, even if punishment's in-principle permissibility is supported by some other rationales 
— desert, deterrence, norm reinforcement, offender reform, or something else — that are suitable as justifications of intentionally burdensome treatment. In other words, perhaps we can separate the question of whether (and why) punishment is permissible from the question of how (or how severely) we may punish in particular cases, and considerations of incapacitation can figure in our answer to the second question. Hart (1959-60), Rawls (1955), Ross (1930: 56-64), and others (see, e.g., Scheid 1997, Bird 1989) have offered hybrid theories of punishment that distinguish various questions and answer them according to different moral or political considerations. If we accept a hybrid theory of punishment along the lines of those endorsed by these scholars, then maybe considerations of incapacitation may yet have a role to play in sentencing.

In my view, a hybrid approach is the most promising strategy for developing a satisfactory justification of punishment (see Hoskins 2018: 88-92). But such a strategy does not pave the way for legitimate appeal to considerations of incapacitation in sentencing. To see why, suppose our answer to the second question above, of how severely we may punish in particular cases, is to appeal to a version of limiting retributivism, so that within the range of not clearly undeserved sentences available in a given case, we are free to appeal to other considerations in setting precise sentencing levels. Suppose also that there are two offenders, Stan and Oliver, who have been found guilty of the same type of conduct, with the same degree of culpability, and thus their cases fall within the same range of not clearly undeserved sentences. Our best riskassessment models suggest that Oliver is more dangerous than Stan, and so we sentence Oliver on the high end and Stan on the low end of the range of not clearly undeserved sentences. When Oliver complains about this state of affairs, we first try to appease him by pointing out that his sentence is at least not clearly undeserved. His concern, however, is with why he is being 
punished more severely than Stan. We explain to him that we regard him as a greater risk than Stan. 'No, no,' Oliver responds, 'You've misunderstood the question. I'm not asking why I'm being confined for longer than Stan. I'm asking why I'm being punished for longer.'

Oliver recognises, as we have seen, that punishment is not merely burdensome treatment but intentionally burdensome treatment, and he is asking what justifies our inflicting this additional intentionally burdensome treatment on him but not on Stan. Even if neither his nor Stan's sentence is clearly undeserved, we might still expect (as Oliver might reasonably expect) some explanation of what justifies the discrepancy in the severity of intentionally burdensome treatment in the two cases. Incapacitation is poorly suited as an answer to this question, because the rationale of incapacitation cannot justify the infliction of intended burdens.

By contrast, considerations of deterrence would be the right sorts of considerations to ground sentencing disparities within the not clearly undeserved range recommended in particular cases by limiting retributivism. Suppose Oliver is punished somewhat more severely than Stan (within the not clearly undeserved range) because unlike Oliver, Stan is no serious threat to reoffend and thus is not in need of specific deterrence, or perhaps because Oliver's case is a higher profile case and has more potential for general deterrent impact. Setting aside whether such sentencing disparities would be justified, my point is just that deterrence is the right sort of consideration to justify what needs to be justified here: namely, a disparity in intentionally burdensome measures. Because maintaining a credible deterrent threat requires that there be some undesirable consequence to offending, and because intending the ends rationally commits us to intending the necessary means, the rationale of deterrence is at least the right sort of consideration to appeal to in answering Oliver's question about why he receives more severe 
intentionally burdensome treatment than does Stan. The same is true of the rationale of retribution and, at least on some accounts, norm reinforcement or offender reform.

The relevant point is that the objection that incapacitation is not a proper rationale for punishment cannot be met by answering the in-principle justification question with some other consideration (desert, rights forfeiture, deterrence, etc.) and then integrating the rationale of incapacitation into the sentencing scheme. Whatever work this rationale does within such a scheme to differentiate sentences in various cases will be unjustified, because as we have seen, incapacitation cannot justify intentionally burdensome treatment. Notice, too, that this objection cannot be avoided by characterising incapacitation as a constraining consideration, rather than a positive rationale, on sentencing within the not-clearly-undeserved range (i.e., sentences should be no less severe than is necessary to incapacitate). To the extent that such a constraining principle ever actually has the effect of ruling out less severe sentences in favour of more severe sentences - that is, insofar as the principle has any bite at all — the state will thereby be inflicting a degree of intentionally burdensome treatment on people without any justification for intending that the treatment be burdensome.

The rationale of incapacitation is thus unsuited as an answer to the question of whether punishment is justified in principle, and it fares no better as a basis for sentencing guidance in particular cases. I conclude, then, that incapacitative punishment, driven by assessments of an offender's riskiness going forward, is unjustifiable. In the next section, I consider various possible responses to the line of objection I have developed here.

\section{Defences of incapacitative punishment}


Given the objection to incapacitative punishment offered in the previous section, what might be said in defence of the rationale of incapacitation? In this section, I consider various possibilities. First, one might object that rather than characterising punishment as involving burdens, we should instead think of it as involving restrictions of liberty. The rationale of incapacitation may not require burdensome treatment (and thus cannot justify intended burdens), but it does require restrictions of certain liberties: freedoms of movement and association, for example. Thus incapacitation does appear to be the right kind of rationale to justify punishment characterised as an intentionally liberty-restricting practice. The problem with this objection is that although criminal sentences typically involve restrictions of liberty, it is in virtue of their being burdensome that these restrictions constitute punishment. If the state's response to crime was to restrict liberties in a way that no one regarded as burdensome (perhaps because the liberties were highly unlikely to be exercised anyway, or because the restrictions were offset by generous forms of compensation), then it seems unlikely that we would regard such a response as punishment. By contrast, if the state's response to crime was to inflict burdensome treatment so quickly or suddenly (perhaps an unexpected punch to an offender's abdomen) that we could not construe this to restrict the offender's liberty in any way, then this nonetheless intuitively would seem to constitute punishment. I conclude, then, that although actual state impositions of punishment will typically restrict liberties and be burdensome, it is in virtue of the burdensomeness, not the liberty restrictions, that they constitute punishment. Thus the objection that punishment is about liberty restrictions, not burdensome treatment, and that incapacitation is the right sort of rationale to figure in a justification of liberty-restricting treatment, fails.

One might instead maintain, contrary to what I have said above, that punishment is not intentionally burdensome. If justifying punishment merely requires justifying a burdensome legal 
response to crime, rather than an intentionally burdensome response, then perhaps the rationale of incapacitation is fit for the job after all. It is difficult to know exactly what to say in response to this objection. I could point out that acceptance of the intentionality feature is widespread among punishment theorists. To take just a few examples, Burgh (1982: 193) writes that punishment involves 'the deliberate and intentional infliction of suffering'. Lucas (1968: 207) states, 'Punishments ... not only are unwelcome but are intended to be, and would lose their point if they were not'. Boonin (2008: 14) writes that 'the punisher intends to harm the recipient of the punishment and does not merely foresee it'. Stephenson (1990: 229) states that an intention of punishment is 'to make [the offender] suffer for having broken the law'. Duff (2001: xiv) describes the typical case of punishment as 'something intended to be burdensome or painful'. And Husak (2011: 1189) writes that 'state sanctions do not qualify as punishments because they happen to impose deprivations and stigmatize their recipients. The very purpose of a punitive state sanction is to inflict a stigmatizing deprivation on the offender.' But if someone nevertheless contends that this common conception of punishment is the wrong one, and that the accurate conception does not involve the intendedness of the burdens, what may be said in response?

I could perhaps also point out that the intentionality feature is crucial to distinguishing punishment from other possible burdensome legal responses to criminal wrongdoing. For example, a state might respond to a burglary by confiscating the offender's ill-gotten goods and returning them to their rightful owner. Or if the goods could not be returned, it might require the offender to offer material compensation to his victim in some other way. The state might also commit the offender to a course of rehabilitative treatment. Any of these legal responses to the burglary would be burdensome. It seems intuitively clear, however, that the state could respond 
in these ways without thereby punishing the offender. The reason is that the burdens associated with these responses, although they may be foreseeable, are not essential to the respective rationales. Thus intending to return ill-gotten goods to their owners, or to require offenders to make restitution to their victims, or to rehabilitate offenders does not rationally commit us to intending that these measures be burdensome.

I maintain, then, that punishment is intended to be burdensome, and that recognising this feature of punishment allows us to distinguish the practice from other types of burdensome legal responses to crime. A critic might respond, I suppose, that punishment is neither intentionally burdensome nor distinct from these other types of responses, because these responses in fact constitute forms of punishment. ${ }^{4}$ Alternatively, she might insist that punishment is not intentionally burdensome and that some other feature of punishment distinguishes it from other burdensome legal responses to crime. The most obvious other feature to cite is that punishment is intended to express societal condemnation or censure (see Feinberg 1970). One problem with citing this alternative feature as the basis for distinguishing punishment from other responses is that many accounts that endorse this expressivist feature regard punishment's burdensomeness as necessary to convey adequately the censure. M. Margaret Falls offers an explanation typical of expressivist accounts:

Just as calmly telling a friend she ought not to have lied to us communicates neither the pain she has caused nor our unqualified insistence that we not be so treated, so the state's verbal or written reprimand with attached explanation would be inadequate. ... Thus, subjection to 'hard treatment' (Feinberg's term), whether it be temporary exclusion from a close friendship or isolation from society, is in no way incidental to holding persons accountable (Falls 1987: 42-43; see also, e.g., Duff 2001: 29-30, and Hampton 1992: 12; but see Hanna 2008).

\footnotetext{
${ }^{4}$ For an argument that compulsory victim restitution constitutes punishment, see Cholbi (2010: esp. 89-92). A full response to Cholbi's account is beyond the scope of this chapter, but it is worth noting that his most plausible argument for his thesis is that compulsory victim restitution is in fact intentionally burdensome. This argument concedes the intentionality feature of punishment.
} 
Insofar as some sort of onerous treatment is necessary to conveying the condemnatory message, then intending to convey the censure rationally commits the state to intending that the treatment be onerous. It's possible, of course, that other accounts might endorse condemnatory responses to crime that are not intentionally burdensome. I am skeptical that such responses would much resemble common conceptions of punishment. But I readily concede that my argument in this chapter would have no purchase against a legal practice of condemnation that is not intentionally burdensome.

Another possible response to my objection to incapacitative punishment would be to accept that punishment is intentionally burdensome, but then to argue that incapacitation is at least in some cases intentionally burdensome. If this is the case, then the rationale of incapacitation may after all be the right sort of rationale to justify intentionally burdensome treatment. Doug Husak contends that at least with respect to the prevention of serious crimes such as terrorism, it is reasonable to think that incapacitative detention is intended to be onerous. For persons 'who pose dangers of megaterrorism,' he writes: 'Surely the state has a punitive intention in preventively detaining these individuals. Few of us would be receptive to a device to prevent megaterrorists from causing enormous destruction that spares them from both deprivation and stigma' (Husak 2011: 1190).

A couple of things are worth noting in response to Husak's argument here. First, notice that his use of the term 'megaterrorist' is unhelpful insofar as it suggests someone who is already guilty of terrorism on a massive scale, rather than someone who might commit terrorist acts in the future. Just as a person is not a murderer until she murders someone, a person is not a megaterrorist until she commits acts of large-scale terrorism. Insofar as Husak's example evokes the intuition he has in mind, namely — that the megaterrorist's detention would be intended as 
burdensome and stigmatizing — we should ask whether this intention is tied to the incapacitative aim or whether another, retributive intuition is lurking here as well: his detention should be onerous because he is a megaterrorist, and megaterrorists do not deserve a light touch. If this is the case, then the detention in Husak's example is not merely preventive but also retributive, and it seems that it is more likely the retributivism rather than the incapacitative aim that is responsible for the intended burdensomeness. This would be consistent with maintaining that mere incapacitation is not a punitive rationale, because incapacitation does not require burdensome treatment. ${ }^{5}$

Suppose, though, that incapacitation can be a punitive aim insofar as merely incapacitative detention may be intended as burdensome. My argument above does not depend on the claim that incapacitation cannot be intentionally burdensome and thus constitute punishment. Rather, whereas Husak in the cited passage is offering an argument about whether incapacitative detention fits within our conception of punishment, my thesis is normative rather than conceptual: the rationale of incapacitation is not the right sort of rationale to justify intentionally burdensome treatment. So even if confinement with the central (or sole) aim of incapacitation is in some cases intentionally burdensome, this fact does not undermine my contention that this intentionally burdensome treatment will not be justified as incapacitation. Again, the rationale of incapacitation may be able to justify confining someone, but it cannot justify intentionally making the confinement burdensome.

Still, one might object that I have employed just the strategy I criticised earlier, namely, appeal to the so-called 'definitional stop' ${ }^{6}$ Essentially, this strategy is an attempt to settle normative debate by definitional stipulation. Hart (1959-60) critiques use of the definitional stop

\footnotetext{
${ }^{5} \mathrm{I}$ argue for this view in Hoskins forthcoming: ch. 2.

${ }^{6}$ In particular, I thank Jesper Ryberg for pushing me on this point.
} 
as a response to the objection that utilitarian accounts of punishment might not be able to rule out punishment of the innocent. Some scholars (e.g., Quinton 1954 and Benn 1958: 332) responded to this objection by insisting that punishment, by definition, is only of the guilty; thus punishment of the innocent would be, by definition, impossible. Hart writes, 'here the wrong reply is: That, by definition, would not be "punishment" and it is the justification of punishment which is in issue' (1959-60: 5). One might object that my argument similarly attempts to resolve a normative question through definitional fiat. After all, I have defended the normative claim that incapacitation is not a legitimate aim of punishment by appeal to a particular element of the definition of punishment (that punishment is intentionally burdensome). Is my argument thus similarly guilty of the definitional stop?

Note that objections to the definitional stop, if they are to have any force, cannot merely be objections to appeals to definition in the context of normative discourse. In particular, if our question is whether some practice is justified, it is surely important to be clear about what it is that we are seeking to justify. The distinctive features of the practice are thus relevant. Instead, the definitional stop, as used in response to the punishing-the-innocent objection, is problematic in two respects: First, many theorists dispute the claim that punishment is only of the guilty (see, e.g., Ten 1987: 16, and Champlin 1976: 85). Rather than merely stipulating this point, it is one that must be supported by arguments. Second, even if punishment is only of the guilty, this does not save utilitarian accounts from the objection that they may permit (or even require) onerous legal treatment of innocent people in the wake of crimes, but under some other name. In other words, if the challenge to utilitarian views is that they might permit unjust burdensome treatment of innocent individuals if the benefits (in terms of deterrence, for example) were sufficiently 
great, it is hardly a satisfactory response to assert that such treatment would not properly be labelled 'punishment' (see Boonin 2008: 44).

My objection to incapacitative punishment, as I have said, is not that incapacitation cannot constitute punishment, but rather that the rationale of incapacitation cannot justify punishment. It is true that my central argument trades on a particular feature of punishment: not that it is only of the guilty, but that it is intentionally burdensome. But I do not claim that incapacitation cannot be intentionally burdensome; rather, I contend that we cannot rely on the aim of incapacitation as justification for imposing onerous legal measures with the intention that they be onerous. I have defended what I take to be the commonly held notion that punishment is intended to be burdensome. But if others want to insist that this is not so, my thesis can be restated this way: intentionally burdensome state responses to crime cannot be justified by appeal to the rationale of incapacitation.

Another sort of argument in favour of incapacitative punishment might appeal to practical, public safety concerns. Protecting members of the public from dangerous offenders requires that we integrate risk assessments into sentencing practices. This is essentially to appeal to necessity: incapacitative punishment is a necessary means to securing the valuable public safety ends. Necessity here might be construed in different ways. Understood as the claim that incapacitative punishment is the only way to achieve the public safety ends, the claim is straightforwardly false. Nonpunitive incapacitation is another means of achieving the same ends. Construing the necessity claim instead as holding that incapacitative punishment is the most effective way to achieve the public safety ends fares no better. There is no plausible reason to believe that incapacitation is more effective insofar as it is intended to be burdensome. Some theorists, particularly in the just war literature, instead construe the necessity condition as a 
requirement that there be no less burdensome means available to secure a given aim (see McMahan 2013-14: 2-3). ${ }^{7}$ The claim that incapacitation through punishment is necessary for public safety clearly fails on this construal of necessity, too, unless one is prepared to argue that, ceteris paribus, intentionally burdensome treatment will typically be less burdensome than unintentionally burdensome treatment. In fact, just the opposite appears more likely to be the case: if the state imposes burdensome treatment intending it to be burdensome, we should expect such treatment to be, other things being equal, more burdensome than treatment imposed without this intention. I conclude, then, that even if certain forms of offender confinement or other restrictive measures are needed to keep supposedly dangerous people away from vulnerable members of the public, such measures need not be intentionally burdensome to serve this end that is, they need not constitute punishment.

Perhaps, though, relying on nonpunitive measures such as civil confinement rather than incapacitative punishment would lead to abuses, as the state could subject citizens to long periods of confinement or other burdensome restrictions without being constrained by dueprocess protections that limit the scope of criminal punishment. As an illustration of this concern, Sexually Violent Predator (SVP) laws in many U.S. states allow for the extended incapacitative detention of people well after they have completed their formal sentences. Courts have tended to defer to legislative claims that these measures are civil rather than criminal measures. As a result, those subject to SVP laws have been denied certain legal protections that are afforded to individuals subject to criminal prosecution and punishment. To note one example, whereas criminal defendants considering a guilty plea have a legal right to be notified of the range of criminal sentence they could face as a result, they are not legally entitled to be informed of the

\footnotetext{
${ }^{7}$ This least-burdensome-means principle is essentially equivalent to the principle of parsimony, which is often cited by sentencing scholars: see, e.g., Frase 2013, esp. p. 32.
} 
additional, potentially permanent civil confinement they may also face due to SVP laws (see, e.g., Roberts 2008 and Janus 2013). If we take seriously concerns about nonpunitive incapacitation's potential to sprawl in its duration or scope with inadequate legal constraints on its implementation, then maybe incapacitative punishment is after all a less burdensome means of protecting public safety.

The problem with this line of argument is that it creates a false dichotomy between, on one hand, civil incapacitative measures as they are often administered in current legal practice and, on the other hand, incapacitative punishment. Although incapacitative measures in current practice are often inadequately constrained by various due-process protections, things need not be this way. Protections such as the notification requirement could be extended to apply to civil incapacitative measures as well as to criminal sentences. In my view, such civil measures would be a less burdensome means than incapacitative punishment of achieving the public safety ends.

A related argument claims that integrating incapacitation into punishment allows for retributivist, desert-based proportionality considerations to constrain the duration and severity of incapacitative measures. One might be tempted to respond to this concern in the same way as to the concern about notification requirements or other due-process protections: we could simply incorporate retributivist proportionality constraints into civil incapacitative measures as well as criminal sentences. I think we should reject this response with respect to retributivist proportionality constraints, however. Retributivist proportionality is concerned with the relation between sentence severity and the seriousness of the prior offence and one's degree of culpability. The rationale of incapacitation suggests a different proportionality consideration: namely, the restrictiveness of the incapacitative measure should be proportionate to the degree of harm it is likely to avert. Thus retributivist proportionality is the wrong sort of proportionality to 
govern risk-reductive incapacitative measures. Besides, considerations of retributivist desert can cut both ways: they might help to protect against excessively severe incapacitative civil measures, but they might instead motivate incapacitative civil measures that are harsher than would be required to achieve the incapacitative aims. Thus I suggest that we should keep considerations of retributivist desert out of incapacitative civil measures.

Finally, one might respond to my argument that there is still a role for the rationale of incapacitation to play in determining the appropriate mode of punishment, if not the appropriate severity. Sentencing theorists typically focus on how to determine what severity of sentence is appropriate in particular cases. Much less attention has been paid to the question of what mode, or form, punishment should take. Here, rather than asking whether one year or 20 years in prison is the appropriate term of punishment, we ask whether prison is the right form of punishment at all, rather than, say, fines, community service, or something else. Perhaps in considering two candidate sentences of (as best we can determine) roughly equal severity but different modes for example, a short jail term or a very heavy financial penalty — incapacitative interests might provide a justification for choosing the mode of punishment more likely to keep the supposedly dangerous person away from vulnerable populations.

Here, I think, we have at last a permissible role for considerations of incapacitation within sentencing decisions. I have argued throughout that the rationale of incapacitation cannot justify the infliction of intended burdens. But in the case at hand, incapacitation is not playing this role. Rather, the intentionally burdensome treatment must be justified entirely on other grounds; incapacitation is only giving us a reason to choose this otherwise-justified form of treatment over that otherwise-justified form of treatment. A justification of the choice of one intentionally burdensome form of treatment over another intentionally (and equally) burdensome 
form of treatment is not itself a justification of intentionally burdensome treatment. Thus appeal to incapacitative interests in this way does not run afoul of the argument I have defended in this chapter. It also does not, as far as I can tell, run afoul of the other objections to incapacitative punishment that I briefly canvassed at the start of the chapter.

I should stress, however, how limited a space this carves out for considerations of incapacitation in sentencing decisions. Incapacitation is only appropriate as, essentially, a tiebreaker between multiple approximately equally severe modes of punishment. It cannot justify a prison term instead of a fine when the prison term is, by our best estimates, clearly more severe than the fine. This would be to subject the offender to a higher quantum of intentionally burdensome treatment based on a rationale unsuited to justifying intentionally burdensome treatment. For proponents of incapacitative punishment, the admission of considerations of incapacitation into sentencing only to decide between multiple equally severe modes of punishment will probably seem an insufficient role for incapacitation to play in sentencing. But any role beyond this is, I contend, unjustifiable.

\section{Conclusion}

One question raised by the preceding account is whether it is enough that incapacitative measures are not intended to be burdensome, or whether they should also be intended not to be burdensome. In other words, could nonpunitive incapacitation be justified if it was imposed with indifference to the foreseeable burdens it would create? Adherence to the least-burdensomealternative principle discussed earlier would seem to suggest that these measures should be intended to be no more burdensome than is required by their incapacitative rationale, insofar as incapacitative measures that are intended to be no more burdensome than their end requires are 
more likely actually to be no more burdensome than is required. One way, of course, to reduce the inevitable burdensomeness of incapacitative measures would be to compensate those subject to them in various ways. Determining whether compensation is appropriate for supposedly dangerous people who are incapacitated, and if so what form the compensation should take and what degree of compensation is justifiable, is beyond the scope of this chapter (see de Keijser 2011: 202-03). Here I merely gesture at this issue as worthy of further consideration.

I have contended that incapacitative punishment is unjustifiable because the rationale of incapacitation is the wrong sort of consideration to justify the infliction of intended burdens. Thus the rationale of incapacitation is unsuited to justifying the institution of punishment in general, and also unsuited to grounding sentencing decisions in particular cases. Instead, incapacitative measures should be treated separately, as foreseeably but not intentionally burdensome civil measures aimed at protecting members of the public.

\section{$\underline{\text { References }}$}

Andenaes, Johannes (1974). Punishment and Deterrence. Ann Arbor. University of Michigan Press.

Armstrong, K.G. (1961). 'The Retributivist Hits Back.' Mind 70(280): 471-90.

Benn, S.I. (1958). 'An Approach to the Problems of Punishment.' Philosophy 33: 325-41.

— (1985). 'Punishment' In Jeffrie Murphy (ed.), Punishment and Rehabilitation $2^{\text {nd }}$ ed. Wadsworth, pp. 8-19.

Bentham, Jeremy (1996[1789]). An Introduction to the Principles of Morals and Legislation. Reprinted in J.H. Burns and H.L.A. Hart (eds.), The Collected Works of Jeremy Bentham: An Introduction to the Principles of Morals and Legislation. Oxford. Clarendon Press. 
Boonin, David The Problem of Punishment (New York: Cambridge University Press, 2008), p. 16.

Burgh, Richard (1982). 'Do the Guilty Deserve Punishment?' The Journal of Philosophy 79(4): $193-210$.

Byrd, B. Sharon (1989). 'Kant's Theory of Punishment: Deterrence in its Threat, Retribution in its Execution.' Law and Philosophy 8(2): 151-200.

Champlin, T.S. (1976). 'Punishment without Offence.' American Philosophical Quarterly 13(1): 85-87.

Cholbi, Michael (2010). 'Compulsory Victim Restitution is Punishment: A Reply to Boonin.' Public Reason 2(1): 85-93.

Cohen, Jacqueline (1984). 'Selective Incapacitation: An Assessment.' University of Illinois Law Review: 253-90.

Corlett, J. Angelo (2001). 'Making Sense of Retributivism.' Philosophy 76(295): 77-110.

de Keijser, Jan (2011). 'Never Mind the Pain, It's a Measure! Justifying Measures as Part of the Dutch Bifurcated System of Sanctions.' In Michael Tonry (ed.), Retributivism Has a Past: Has It a Future? Oxford. Oxford University Press, pp. 188-213.

Dubber, Markus Dirk (1995). 'Recidivist Statutes as Arational Punishment.' Buffalo Law Review 43: 689-724.

Duff, R.A. (2001). Punishment, Communication, and Community. Oxford. Oxford University Press.

Ewing, A.C. (1927). 'Punishment as Moral Agency: An Attempt to Reconcile the Retributive and the Utilitarian View.' Mind 36(143): 292-305. 
Falls, M. Margaret (1987). 'Retribution, Reciprocity, and Respect for Persons.' Law and Philosophy 6(1): 25-51.

Fazell, Seena, Jay P. Singh, Helen Doll, and Martin Grann (2012). 'Use of risk assessment instruments to predict violence and antisocial behaviour in 73 samples involving 24,827 people: systematic review and meta-analysis.' BMJ 345: 1-12.

Feinberg, Joel (1970). 'The Expressive Function of Punishment.' In Doing and Deserving: Essays in the Theory of Responsibility. Princeton. Princeton University Press.

Frase, Richard S. (2013). Just Sentencing: Principles and Procedures for a Workable System. Oxford: Oxford University Press.

Hampton, Jean (1984). 'The Moral Education Theory of Punishment.' Philosophy and Public Affairs 13(3): 208-38.

_ (1992). 'An Expressive Theory of Retribution.' In W. Cragg (ed.), Retributivism and Its Critics. Stuttgart. Franz Steiner, 1-25.

Hanna, Nathan (2008). 'Say What? A critique of expressive retributivism.' Law and Philosophy 27: $123-50$.

_ (2014). 'Facing the Consequences.' Criminal Law and Philosophy 8(3): 589-604.

Hart, H.L.A (1959-60). 'Prolegomenon to the Principles of Punishment.' Proceedings of the Aristotelian Society 60: 1-26.

Hoskins, Zachary (2011). 'Deterrent Punishment and Respect for Persons.' Ohio State Journal of Criminal Law 8: 369-84.

— (2018). 'Multiple-Offense Sentencing Discounts: Score One for Hybrid Accounts of Punishment.' In Jesper Ryberg, Julian V. Roberts, and Jan W. de Keijser (eds.), Sentencing Multiple Crimes. New York. Oxford University Press, pp. 75-93. 
_ (forthcoming). Beyond Punishment? A Normative Account of the Collateral Legal Consequences of Conviction. New York: Oxford University Press.

Husak, Douglas (2011). 'Lifting the Cloak: Preventive Detention as Punishment.' San Diego Law Review 48: 1173-1204.

Janus, Eric S. (2013). 'Preventive Detention of Sex Offenders: The American Experience versus International Human Rights Norms.' Behavioral Sciences and the Law 31: 328-43.

Kant, Immanuel (1996[1785]). Groundwork of the Metaphysics of Morals. In Mary Gregor (trans. and ed.), The Cambridge Edition of the Works of Immanuel Kant: Practical Philosophy. Cambridge. Cambridge University Press.

Lieb, Roxanne, Vernon Quinsey, and Lucy Berliner (1998). 'Sexual Predators and Social Policy.' Crime and Justice 23: 43-114.

Lucas, J.R. (1968). 'Or Else.' Proceedings of the Aristotelian Society 69: 207-22.

McMahan, Jeff (2013-14). 'Proportionate Defense.' Journal of Transnational Law and Policy 23: $1-36$.

Monahan, John (1981). Predicting Violent Behavior: An Assessment of Clinical Techniques. Beverly Hills, Calif. Sage Publications, 1981.

Morris, Norval (1974). The Future of Imprisonment. Chicago. University of Chicago Press.

Morris, Norval, and Michael Tonry (1990). Between Prison and Probation: Intermediate Punishments in a Rational Sentencing System. New York. Oxford University Press.

Quinton, Anthony (1954). 'On Punishment.' Analysis 14: 33-42.

Rawls, John (1955). 'Two Concepts of Rules.' The Philosophical Review 64(1): 3-32. 
Roberts, Jenny (2008). 'The Mythical Divide Between Collateral and Direct Consequences of Criminal Convictions: Involuntary Commitment of "Sexually Violent Predators".' Minnesota Law Review 93: 670-740.

Robinson, Paul (2001). 'Punishing Dangerousness: Cloaking Preventive Detention as Criminal Justice,' Harvard Law Review 114: 1429-56.

Ross, W.D. (1930). The Right and the Good. Oxford. Oxford University Press.

Scheid, Don E. (1997). 'Constructing a Theory of Punishment, Desert, and the Distribution of Punishments.' Canadian Journal of Law and Jurisprudence 10: 441-506.

Slobogin, Christopher (2003). 'A Jurisprudence of Dangerousness.' Northwestern University Law Review 98:1-62.

Stephenson, Wendell (1990). 'Fingarette and Johnson on Retributive Punishment.' The Journal of Value Inquiry 24: 227-33.

Ten, C.L. (1987). Crime, Guilt, and Punishment: A Philosophical Introduction. Oxford. Clarendon Press.

Zimring, Franklin E., and Gordon Hawkins (1995). Incapacitation: Penal Confinement and the Restraint of Crime. Oxford. Oxford University Press. 